(REVIEW ARTICLE)

\title{
Aliskiren: analytical review for estimation in pharmaceutical formulations
}

Patil Sheetal Vikas *, Nalawade Anup Kishor, Nalawade Rohit Deepak, Ghode Shweta Prashant

Rasiklal M. Dhariwal Institute of Pharmaceutical Education and Research, Acharya Anand Rushiji Marg, Chinchwad, Pune- 411019, Maharashtra, India.

Publication history: Received on 24 March 2020; revised on 29 March 2020; accepted on 30 March 2020

Article DOI: https://doi.org/10.30574/wjarr.2020.6.1.0078

\begin{abstract}
Aliskiren (AL) is classified as angiotensin converting enzyme inhibitors (ACEIs) used as antihypertensive drug it acts by dilating blood vessel. These dilation of blood vessel caused due to the renin inhibition. There have been numerous methods developed so far for quantitative estimation of AL in bulk and pharmaceutical dosage form. Pharmaceutical analytical methods include UV Visible Spectrophotometry, Reversed Phase High Performance Liquid Chromatography and hyphenated techniques like Liquid chromatography- Mass Spectrometry. This review paper includes various publications focuses on advanced analytical methods. The chromatographic methods primarily RP-HPLC and LC-MS found more promising and sensitive compared to other pharmaceutical methods.
\end{abstract}

Keywords: Aliskiren; High performance liquid Chromatography (HPLC) and Hyphenated techniques

\section{Introduction}

Aliskiren (AL) is chemically (2S,4S,5S,7S)-5-amino-N-(2-carbamoyl-2,2-dimethylethyl)-4-hydroxy-7-\{[4-methoxy-3(3-methoxypropoxy)phenyl]methyl-8-methyl-2-(propan-2-yl) nonanamide. It was approved by the U.S. Food and Drug Administration in 2007 for the treatment of hypertension [https://www.drugbank.ca/drugs/DB09026/Last accessed on28/01/2020].<smiles>COCCCOc1cc(C[C@H](C[C@H](N)[C@H](O)C[C@H](C(=O)NCC(C)(C)C(N)=O)C(C)C)C(C)C)ccc1OC</smiles>

Figure 1 Structure of Aliskiren

Aliskiren is a direct renin inhibitor, decreasing plasma renin activity (PRA) and inhibiting the conversion of angiotensinogen to angiotensin I (Ang I) [https://www.drugbank.ca/drugs/DB09026/ Last accessed on28/01/2020, 1]. It is used for the treatment of mild to moderate hypertension. It may be used alone or in combination with other antihypertensive agents.

\footnotetext{
*Corresponding author: Patil Sheetal Vikas email ID: sheetal_dhir15@rediffmail.com
} 
Methods for pharmaceutical analysis are significantly much simpler comparatively with metabolites in biological samples as in urine, blood and plasma. The estimation of a drug is to a great extent important in complex matrices because the pharmaceutical product quality is directly associated to patient wellbeing. Analytical methods play a key role in the drug development and pharmaceutical control, to ensure a high efficacy and safety for patients [2].

\section{Analytical methods for estimation of Aliskiren}

\subsection{UV-visible methods}

However, UV-Visible Spectrophotometry method is not able to give broad spectra for estimation of certain drugs, it has accuracy, speed, gives sensitive and precise results. It consists of calculating and plotting first order and second order derivative of the mathematical expression of a spectral curve and area under curve.

Nita Yadav and Anju Goyal [3] have developed three spectrophotometric methods as method I: zero order derivative, Method II: first order derivative and method III: area under curve.

Table 1 Results of above mentioned methods of UV

\begin{tabular}{llll}
\hline Parameters & Method I & Method II & Method III \\
\hline $\begin{array}{l}\text { Wavelength } \\
\text { Linearity Range }(\mu \mathrm{g} / \mathrm{ml})\end{array}$ & 279 & 289 & $269-289$ \\
$\begin{array}{l}\text { Regression equation } \\
(\mathrm{Y}=\mathrm{mx}+\mathrm{c})\end{array}$ & $\mathrm{y}=0.006 \mathrm{x}+0.002$ & $\mathrm{y}=0.0006 \mathrm{x}-0.001$ & $\mathrm{y}=0.034 \mathrm{x}-0.104$ \\
$\begin{array}{l}\text { Correlation coefficient }(\mathrm{r} 2) \\
\text { \% Label claim }\end{array}$ & 0.999 & 0.999 & 0.999 \\
\%RSD & $98.54 \pm 0.50$ & $100.32 \pm 1.35$ & $100.38 \pm 0.53$ \\
\hline
\end{tabular}

Micheli Wrasse-Sangoi [4] et al. has developed UV method was linear in the range between 40 and $100 \mu \mathrm{g} \mathrm{m}-1(r 2=$ 0.9997, $n=7$ ) and exhibited suitable specificity, accuracy, precision, and robustness. It is simple, it has low cost, and it has low use polluting reagents. Therefore, the proposed method was successfully applied for the assay and dissolution studies of aliskiren in tablet dosage forms, and the results were compared to a validated RP-LC method, showing nonsignificant difference $(P>0.05)$.

Mai A. Ramadan [5,6] et al has developed two method based on the reaction of ALS with o-phthalaldehyde (OPA) and nacetylcysteine (NAC) in a basic buffer (method I) and with ninhydrin in the presence of ascorbic acid (0.1\%) as a reducing agent, in slightly acidic media (phosphate buffer $0.2 \mathrm{M}, \mathrm{pH} 6.0$ ) at $90^{\circ} \mathrm{C}$ for $20 \min (\operatorname{method}$ II). These are summarized in table no. 2 .

Table 2 A summary of above mentioned methods

\begin{tabular}{llllll}
\hline Parameters & $\lambda \max (\mathbf{n m})$ & Conc. Range $(\boldsymbol{\mu g} / \mathbf{m l})$ & $\mathbf{r} 2$ & \% recovery & reference \\
\hline Method I & 335 & $10-200$ & 0.9996 & $99.45 \pm 0.76$ & 5 \\
Method II & 569 & $10-170$ & 0.9982 & $100.15 \pm 1.29$ & 6 \\
\hline
\end{tabular}

\subsection{Chromatographic methods and Hyphenated Techniques}

This method encompasses a device and important group of methods that permit the scientist to separate closely related components of complex mixtures, many of these separations are impossible by other means. 


\subsubsection{HPLC methods}

Nita Yadav [7] et al has been reported a reverse phase high performance liquid chromatographic method for the estimation of Aliskiren in tablet dosage form with LC system used consists of pump (Model Shimadzu; LC-10 AT VP) with universal loop injector (Rheodyne 7725) of injection capacity $20 \mu$ l.

K. Satish Babu [8] et al. has developed a reverse phase high performance liquid chromatographic method for the estimation of Aliskiren in tablet dosage form with HPLC from Shimadzu (version LC-2010C), equipped with a quaternary pump and a thermostat column jacket for maintaining ambient temperature during chromatographic separation was used for analysis.

Shalini Pachauri [9] et al have been reported gradient high performance chromatographic method with Waters Alliance HPLC system (waters 2695 separation module), equipped with a photo diode array detector (Waters 2996 photo diode array detector).

G. Kumara Swamy [10] et al reported RP-HPLC method for estimation of Aliskiren in bulk and tablet with Shimadzu HPLC system containing SPD-10 ATVP pump and SPD-10AVP UV-Visible detector.

Table 3 Reverse phase HPLC methods

\begin{tabular}{|c|c|c|c|c|c|c|c|c|}
\hline Column & $\begin{array}{l}\text { Dimension } \\
(\mathbf{m m} \times \mathbf{m m} \times \\
\mu)\end{array}$ & Mob phase & $\begin{array}{l}\lambda \max \\
(\mathrm{nm})\end{array}$ & $\begin{array}{l}\text { Linearity } \mu \mathrm{g} / \\
\mathrm{ml}\end{array}$ & $\begin{array}{l}\% \\
\text { Recove } \\
\text { ry }\end{array}$ & Detector & $\mathbf{r}^{2}$ & $\begin{array}{l}\text { Referenc } \\
\text { e }\end{array}$ \\
\hline $\begin{array}{l}\text { C8 } \\
\text { Chromasil }\end{array}$ & $150 \times 4.6,5$ & $\begin{array}{l}\text { phosphate } \\
\text { buffer, } \\
\text { methanol and } \\
\text { CAN } \\
(55: 10: 35)\end{array}$ & 220 & $30-150$ & $\begin{array}{l}100.06- \\
100.43\end{array}$ & PDA & 0.9999 & [7] \\
\hline \multirow[t]{2}{*}{$\begin{array}{l}\text { Water } \\
\text { Xbridge } \\
\text { C18 column }\end{array}$} & $150 \times 4.6,5$ & $\begin{array}{l}0.03 \% \text { trifluro } \\
\text { acetic acid in } \\
\text { water }\end{array}$ & $\begin{array}{l}230 / 25 \\
4\end{array}$ & $1-100$ & $\begin{array}{l}98.36- \\
99.12\end{array}$ & $\begin{array}{l}\text { Duel } \\
\text { Wavelengt } \\
\mathrm{h}\end{array}$ & 0.999 & [8] \\
\hline & & $\begin{array}{l}\text { and } 0.03 \% \\
\text { trifluroaceticac } \\
\text { id } \\
\text { in ACN and } \\
\text { water }(95: 5)\end{array}$ & & & & Detector & & \\
\hline $\begin{array}{l}\text { PUROSPHER } \\
\text { E STAR RP } \\
18 \mathrm{e}\end{array}$ & $150 \times 4.6,5$ & $\begin{array}{ll}0.2 \% \mathrm{v} / \mathrm{v} & \text { TEA } \\
\text { buffer } & \text { (pH: } \\
\text { 3.0): ACN } & \end{array}$ & 215 & $20-120$ & - & PDA & 0.9993 & [9] \\
\hline $\begin{array}{l}\text { Phenomena } \\
\text { x LunaC18 } \\
\text { column }\end{array}$ & $150 \times 4.6,5$ & $\begin{array}{l}\text { phosphate } \\
\text { buffer pH } 3.0 \text { : } \\
\text { Acetonitrile } \\
(60: 40, v / v)\end{array}$ & 293 & $5-30$ & 101.10 & UV & 0.9999 & [10] \\
\hline
\end{tabular}

Sigala Ashok [11] et al have been reported a LC method for determination of enantiomeric impurity (enantiomeric separation of (R)-aliskiren from (S)-aliskiren) in Aliskiren in bulk drug sample.

The method was developed by using a mixture of acetonitrile-n-butylamine 100:0.1(v/v) as a mobile phase with a flow rate maintained at $1.0 \mathrm{~mL} / \mathrm{min}$ with column used was a Chiralpak-IC $(250 \times 4.6 \mathrm{~mm})$ with $5-\mu$ particles. Ultraviolet detection was carried out at $228 \mathrm{~nm}$. Resolution between the two enantiomers was greater than 3.0. The LC system used for method development and method validation was a Waters 2695 binary pump plus auto sampler and a 2996 photodiode array detector. The details of study with different columns and mobile Phase is summarized in Table No.4. 
Table 4 Chiral selectivity results

\begin{tabular}{|c|c|c|c|}
\hline Column & Mobile Phase & Retention time (min) & Resolution \\
\hline Chiralpak AD-H & 80:20 n-hexane-isopropyl alcohol; & 3.9 and 3.9 & No resolution \\
\hline Chiralpak OD-H & $\begin{array}{l}80: 20 \mathrm{n} \text {-hexane-isopropyl alcohol; } \\
1 \mathrm{~mL} / \mathrm{min}\end{array}$ & 3.4 and 3.2 & No resolution \\
\hline Chiralpak -OJ & $\begin{array}{l}80: 20 \text { n-hexane-isopropyl alcohol; } 1 \\
\mathrm{~mL} / \mathrm{min}\end{array}$ & 3.2 and 3.2 & No resolution \\
\hline Chiralpak -IA & $\begin{array}{l}\text { 80:20:0.1 n-hexane-isopropyl alcohol- } \\
\text { diethyl amine; } 1 \mathrm{~mL} / \mathrm{min}\end{array}$ & 17.09 and 18.45 & Less than 1.0 \\
\hline Chiralpak -IB & $\begin{array}{l}\text { 80:20:0.1 n-hexane-isopropyl alcohol- } \\
\text { diethyl amine; } 1 \mathrm{~mL} / \mathrm{min}\end{array}$ & 4.32 and 4.32 & No resolution \\
\hline Chiralpak -IC & $\begin{array}{l}\text { 80:20:0.1 n-hexane-isopropyl alcohol- } \\
\text { diethyl amine; } 1 \mathrm{~mL} / \mathrm{min}\end{array}$ & 4.75 and 4.75 & No resolution \\
\hline Cyclobond & $\begin{array}{l}90: 100.1 \% \text { acetic acid-acetonitrile, } \mathrm{pH} \\
4.0 \text { with ammonia } \\
\text { solution. }\end{array}$ & 2.25 and 2.25 & No resolution \\
\hline Chiral AGP & $\begin{array}{l}95: 5 \quad 0.01 \mathrm{M} \text { ammonium acetate- } \\
\text { methanol, } \mathrm{pH} 4.5 \text { with acetic acid }\end{array}$ & 5.7 and 6.06 & Less than 1.0 \\
\hline Chiralpak -IA & $\begin{array}{l}\text { 95:5:0.1 n-hexane-Ethanol } \quad \text {-n- } \\
\text { butylamine }\end{array}$ & 16.32 and 17.77 & 1.54 \\
\hline $\begin{array}{l}\text { Chiralpak -IC } \\
\text { (RP mode) }\end{array}$ & 100:0.1 acetonitrile-n-butylamine & 14.53 and 11.81 & 3.23 \\
\hline
\end{tabular}

Belal F. [12] et al have been reported HPLC method for the determination of aliskiren in human plasma through derivatization with 1-naphthyl isocyanate. The separation was achieved on a C18 column using a mobile phase consisting of acetonitrile/water/phosphoric acid (45:55:0.01, v/v/v, pH 3.2) in a flow rate of $1 \mathrm{ml} / \mathrm{min}$ with UV detection at $230 \mathrm{~nm}$. Caffeine was used as an internal standard. The method was linear over the concentration range of 5-400 ng/ml. The percentage recovery was in the range $97.1-98.6 \%$.

Lefevrea and Gauronb [13] proposed HPLC method with fluorometric detection for aliskiren determination in blood serum and urine. The samples were extracted in an automated way from $400 \mu \mathrm{l}$ of serum or urine with methyl alcoholacetic acid mixture (99:1, v/v) on 100-mg Bond-ElutCN cartridges using the Gilson ASPEC system. Chromatographic separation was conducted on LiChrospher $100 \mathrm{RP} 85-\mu \mathrm{m}$ particle size packed analytical column $(25 \times 0.4 \mathrm{~cm}$ I.D.). The mobile phase was acetonitrile-0.01 M potassium dihydrogen phosphate $(65: 35, \mathrm{v} / \mathrm{v})$ mixture with a flow rate of 0.8 $\mathrm{ml} \cdot \mathrm{min}-1$, fluorometric detection with excitation and emission wavelength of 280 and $330 \mathrm{~nm}$, respectively, was used, an internal standard was (2S,4S,5S,7S)-N-butyl-5-amino-4-hydroxy-2,7-diisopropyl-8-[3-(3-methoxypropoxy)-4methoxyphenyl] octanamide hydrochloride (CGP-56962A). Linearity range for the proposed method was 4.5-450 $\mathrm{ng} \cdot \mathrm{mL}-1$ in serum, and 9.0-900 $\mathrm{ng} \cdot \mathrm{mL}-1$ in urine, quantification limits were $4.5 \mathrm{ng} \cdot \mathrm{mL}-1$ and $9.0 \mathrm{ng} \cdot \mathrm{mL}-1$, respectively.

\subsubsection{Hyphenated Techniques}

A couple of decades ago, Hirschfield introduced the term "hyphenation" to refer to the on-line combination of a separation technique and one or more spectroscopic detection techniques. The hyphenation does not always have to be between two techniques; the coupling of separation or detection techniques, more recently, so called double hybrid e.g. LC-PDA-MS, LC-MS-MS, LC-NMR-MS instruments have become available and have been applied to pharmaceutical problem solving [14].

HPLC MS/MS method was used for aliskiren determination in blood serum, in which benazepril was applied as an internal standard. Samples preparation involved an addition of $500 \mathrm{~mL}$ phosphoric acid $(2 \%, \mathrm{v} / \mathrm{v})$ and $10 \mathrm{~mL}$ methanol benazepril solution to $100 \mu \mathrm{L}$ serum. The whole was mixed, and then centrifuged at a temperature of $40^{\circ} \mathrm{C}$ for $10 \mathrm{~min}$. The extraction was performed using Oasis W MCX solid-phase extraction (SPE) cartridges. SPE system was initially 
prepared by rinsing with ammonia solution in methanol $(10 \%, \mathrm{v} / \mathrm{v})$, and then methanol and $2 \%$ formic acid. Acidified serum samples were applied on SPE columns, and rinsed with $2 \mathrm{~mL}$ of $2 \%$ formic acid and $2 \mathrm{~mL}$ methanol. An analyte was eluted by three-times system rinsing with $0.5 \mathrm{~mL}$ and once with $0.3 \mathrm{~mL}$ of ammonia solution in methanol (10\%, $\mathrm{v} / \mathrm{v}$ ). Eluent was evaporated to dry form in nitrogen atmosphere, and then dissolved in $100 \mu \mathrm{L}$ of mobile phase, which was methanol-water-formic acid mixture (75:25:0.005, v/v/v). Such prepared samples were subjected to separation on XselectTM C18 CSH column, with mobile phase flow rate of $0.4 \mathrm{ml} \cdot \mathrm{min}^{-1}$, total time of analysis was about $5 \mathrm{~min}$, and the results obtained were characterized by a high precision and accuracy. The linearity range was $0.146-1200 \mathrm{ng} \cdot \mathrm{ml}^{-1}$. Due to an application of small volume of the examined sample, the elaborated method may be successfully used in monitoring of aliskiren level in pediatrics [15].

The another method of aliskiren determination in the saliva of healthy volunteers was conducted using LC-ESIMS/ MS. Sample preparation for the study involved mixing of $100 \mu \mathrm{L}$ of undiluted saliva with $10 \mu \mathrm{L}$ of internal standard, which was benazepril hydrochloride solution (166 ng/ml) and $490 \mu \mathrm{L}$ formic acid $(2 \%, \mathrm{v} / \mathrm{v})$. The sample was subject to extraction to solid phase (Oasis R MCX) using SPE columns which were suitably prepared by rinsing with $1 \mathrm{~mL}$ of a mixture of ammonia solution-methanol-acetonitrile $(10: 45: 45, \mathrm{v} / \mathrm{v} / \mathrm{v})$, and then $1 \mathrm{~mL}$ of methanol and finally equilibrated with $2 \%$ formic acid. The samples were applied on such prepared SPE system and eluted with $1 \mathrm{~mL}$ of formic acid $(2 \%, \mathrm{v} / \mathrm{v})$ followed by $1 \mathrm{~mL}$ methanol- acetonitrile $(50: 50, \mathrm{v} / \mathrm{v})$. Analyte was released by elution using 0.5 $\mathrm{mL}$ (three times) and one time $0.4 \mathrm{~mL}$ of a mixture of ammonia solution-methanol-acetonitrile $(10: 45: 45, \mathrm{v} / \mathrm{v} / \mathrm{v})$. Eluent was evaporated at the temperature of $40^{\circ} \mathrm{C}$. The sample was diluted using $100 \mu \mathrm{L}$ mixture of acidified methanol-water $(20: 80, \mathrm{v} / \mathrm{v})$. Chromatographic separation was carried out on a Xselect ${ }^{\mathrm{TM}}$ CSH C18 column $(3.0 \times 150 \mathrm{~mm}, 3.5 \mu)$ protected by a corresponding Xselect ${ }^{\mathrm{TM}} \mathrm{CSH}$ C18 guard column $(3.0 \times 20 \mathrm{~mm}, 3.5 \mu \mathrm{m})$. Time of analysis was 7.5 min with a mobile phase gradient of acidified methanol (A) and acidified water (B) (each $0.1 \%$ formic acid, v/v) to separate the compounds. Gradient was as follows: starting with $30 \%$ of A, after $0.2 \mathrm{~min} 50 \% \mathrm{~A}$, at 6 min $80 \% \mathrm{~A}$, at $6.3 \mathrm{~min} 100 \% \mathrm{~A}$, decreased to $50 \% \mathrm{~A}$ at $7 \mathrm{~min}$ and staying at $50 \%$ for the rest of the run time. The elaborated procedure is characterized by a wide range of linearity, i.e. $0.586-1200 \mathrm{ng} \cdot \mathrm{mL}-1$, low quantification limit, as well as good precision and accuracy. Based on the results obtained the authors concluded that the concentration of aliskiren in human saliva is measurable, but considerably lower than expected [16].

\section{Conclusion}

In this paper, recent analytical methods employed for quantitative analysis of aliskiren in pharmaceutical formulations were reviewed. Several techniques like UV - Visible spectrophotometry including Area under curve, zero order, first order, colorimetric methods, Chromatographic methods primarily (high performance liquid chromatography) and hyphenated techniques were reviewed. Liquid chromatography is the major techniques that have been used, of which it is observed a development to use quicker techniques with cost savings and lessening in solvent consumption. From this work, it has been observed that High Performance Liquid Chromatography is extensively utilized for estimation of Aliskiren in bulk material and pharmaceutical formulations. Further there has been always greater need to develop more sophisticated method to determine content of aliskiren in bulk and pharmaceutical dosage form.

\section{Compliance with ethical standards}

\section{Acknowledgments}

We wish to acknowledge RMDIPER for providing the necessary facility.

\section{Disclosure of conflict of interest}

We declare no conflict of interest.

\section{References}

[1] Nussberger J, Wuerzner G, Jensen C and Brunner HR. (2002). Angiotensin II suppression in humans by the orally active renin inhibitor Aliskiren (SPP100): comparison with enalapril. Hypertension, Jan 39(1), E1-8.

[2] Pluym A, Van Ael W and De Smet M. (1992). Capillary electrophoresis in chemical/pharmaceutical quality control. TrAC Trends in Analytical Chemistry, 11(1), 27-32.

[3] Yadav N and Goyal A. (2018). Method development and validation of Aliskiren in tablet by UV spectrophotometric methods. International Journal of Pharmaceutical Chemistry and Analysis, april- June 5(2), 89-93. 
[4] Micheli Wrasse-Sangoi, Leonardo Trevisan Secretti, Isabel Fração Diefenbach e Clarice Madalena Bueno Rolim (2010). Development and validation of an UV spectrophotometric method for the determination of Aliskiren in tablets, Quim. Nova, 33(6), 1330-1334.

[5] Ramadan MA and Abuiriban MB. (2013). Development and Validation of a spectrophotometric method for determination of Aliskiren in tablets using 0-phthalaldehyde, International Journal of Pharmaceutical Science Review and Research, 21(1), 333-337.

[6] Ramadan MA and Abuiriban MB. (2013). Spectrophotometric determination of Aliskiren in bulk and tablets using ninhydrin, Indo American Journal of Pharmaceutical Research, 3(8), 6419-6429.

[7] Yadav N and Goyal A. (2018). Method development and validation for the estimation of Aliskiren in pharmaceutical dosage form by RP-HPLC, Organic and Medicinal Chemistry IJ, 5(3), 001-005.

[8] K Satish Babu, J.V.L.N.S. Rao, and K. Vijaya Bhargava. (2011). A simple and sensitive method for the determination of Aliskiren hemifumarate using Hplc-UV detection, Rasayan, J chem, 4(2), 285-288.

[9] Pachauria S, Paliwalb S, Srinivasa KS, Singha Y and Jaina V. (2010). Development \& validation of hplc method for analysis of some antihypertensive agents in their pharmaceutical dosage forms, Journal of Pharmaceutical Science \& Research, 2(8), 459-464.

[10] Swamy GK, Sheshagiri Rao JVLN, Rajendra Kumar JM, Ashok Kumar U,. Bikshapathi DVRN and Vinay kumar D. (2011). Analytical method development and validation of aliskiren in bulk and tablet dosage form by RP- HPLC method, Journal of Pharmacy Research, 4(3), 865-867.

[11] Sigala A, Varma MS and Srinivasan S. [2012]. A validated lc method for the determination of the enantiomeric purity of aliskiren hemifumarate in bulk drug samples, Journal of Chromatographic Science,50, 99-802.

[12] Belal F, Walash M, El-Enany N and Zayed S. (2013). Highly sensitive HPLC method for assay of aliskiren in human plasma through derivatization with 1-naphthyl isocyanate using UV detection, Journal of Chromatography B, 933, 24-29.

[13] Lefevre G and Gauron S. (2000). Automated quantitative determination of the new renin inhibitor CGP 60536 by high-performance liquid chromatography, Journal of Chromatography B, 738, 129-136.

[14] Patil SV and Dr. Barhate SD. (2015). Hyphenated Technique: An overview, World Journal of Pharmaceutical Research, 4(2), 214-225.

[15] Burckhardt BB, Ramusovic S, Tins J and Laeer S. (2013). Determination of aliskiren in human serum quantities by HPLC-tandem mass spectrometry appropriate for pediatric trials, Biomedical Chromatography, 27, 477-486.

[16] Burckhardt BB, Tins J and Laeer S. (2014). Liquid chromatography-tandem mass spectrometry method for determination of aliskiren in saliva and its application to a clinical trial with healthy volunteers, Journal of Pharmaceutical and Biomedical Analysis, 96, 118-126.

\section{How to cite this article}

Patil SV, Nalawade AK, Nalawade RD, Dr. Ghode SP (2020). Aliskiren: analytical review for estimation in pharmaceutical formulations. World Journal of Advanced Research and Reviews, 6(1), 19-24. 